\title{
Deliberate Vocabulary Learning from Word Cards
}

\author{
Darrell Wilkinson \\ Tampere University, Tampere, Finland
}

\begin{abstract}
While word cards are a widely supported method of deliberately studying foreign language vocabulary, there is a surprising lack of research-based evidence supporting them. This paper first reviews some of the key literature on word cards and then briefly describes two experiments concerning word card methodology. The first experiment described in this paper examined the learning outcomes of making word cards while the second experiment compared the use of self-made word cards with premade cards. The results of the first study indicated that the simple process of making word cards results in significant shortterm vocabulary learning, but this new knowledge is sensitive to attrition if no further study is carried out soon after making the cards. The results of the second experiment indicated that while both methods are effective in the short and long-term, learners may be better studying from premade cards. Taken together, the results offer support for the use of word cards for foreign language vocabulary learning.
\end{abstract}

\section{Introduction}

Vocabulary knowledge is a central component of language acquisition and communication (Nation, 2013; Schmitt, 2008). In order for learners to master the thousands of words needed to become competent in a foreign language, most researchers now recommend a combination of both deliberate and incidental techniques (Folse, 2004, 2011; Laufer, 2003; Nation, 2013; Schmitt, 2008). While incidental vocabulary learning is very useful for consolidating and broadening the knowledge of previously studied vocabulary, deliberate learning techniques are a much more time-efficient method for learning the meaning of new words or phrases. The literature and experiments discussed in this paper are focused on deliberate vocabulary study, something which involves learners engaging in activities with the specific purpose of acquiring new vocabulary knowledge (Nation, 2013; Schmitt, 2008). Specifically, I investigate the use of word cards as a deliberate study method.

The reason for this focus came from (1) a belief in the necessity of deliberate vocabulary study in general, (2) the theoretical support regarding the strength of word cards described by Mondria and Mondria-de Vries (1994) and Nation (2013), and (3) the important and surprising gaps in the literature regarding word cards, especially those pointed out by Nation and Webb (2011). 


\section{Word Card Design}

In their most basic form, word cards involve having the target language word written on one side, with the native language meaning of the word written on the other side. However, depending on learner or teacher preferences, other information such as part of speech, collocations, pronunciation information, or example sentences can also be included on the cards (Folse, 2004; Hulstijn, 2001; Nation, 2013; Nation \& Webb, 2011). The most common type of word card is the traditional paper version, but there are a great number of digital word card programs and smartphone applications available these days, such as Quizlet. Based on my analysis and qualitative data collected from students, when using paper word cards, students can easily add whatever information they like, but some of the digital versions offer less freedom or ease of input.

\section{Theoretical Support for Word Cards}

Many vocabulary experts support the use of word cards (Laufer, 2003; Mondria \& Mondria-de Vries, 1994; Nation, 2013; Waring, 2004); however, Paul Nation is probably the most well-known and ardent supporter of word cards for repeated deliberate vocabulary learning. Under the four-strand approach, this method falls under the language-focused learning strand, something often also referred to as deliberate vocabulary learning (Nation, 2013). Generally, while other deliberate study techniques such as learning from lists or notebooks are generally seen as effective for building vocabulary knowledge in a relatively short period of time (Nation, 2013; Nation \& Waring, 1997; Schmitt \& Schmitt, 1995; Walters \& Bozkurt, 2009), studying from word cards has been suggested to be a more effective method (Mondria \& Mondria-de Vries, 1994; Nakata, 2008; Nation, 2013; Waring, 2004).

Overall, while any deliberate learning approach will produce positive learning outcomes, word cards are commonly seen as a more effective option due to the unique affordances they provide, as discussed below.

The success of word cards can be attributed to a number of factors described by Nakata (2008), Nation (2013), and Mondria and Mondria-de Vries (1994). First, by having the L1 and L2 forms of a word written on different sides, learners are given opportunities for retrieval, that is, retrieving the meaning of the word from memory. Word lists or notebooks provide both the L1 and L2 information sideby-side, meaning that learners must cover up one of the forms in order to retrieve the other language meaning from memory, something that many students might not do. However, because the L2 and L1 forms are presented on different sides, when studying from word cards, learners are forced to try to recall the word before checking if they are correct, and this process is deemed more efficient. Learners are essentially giving themselves a mini test each time they study with their word cards, and as a result, positive test effects are likely to take place. Word cards also afford a time-efficient method for repeated rehearsal because students can quickly study the words again and again without the use of any other study aids. Furthermore, expanded spaced rehearsal can be implemented more easily than when using notebooks or word pair lists. Learners can separate their word card packs in order to focus on more unknown or new words, spending less time on easier or better-known 
words that would be presented together on a list. Also, as words are presented separately and can be regularly shuffled, there is little chance of the list effect or serial learning. Finally, as Mondria and Mondria-de Vries (1994) point out, the word card system is flexible in terms of content; a variety of information such as translations, synonyms, language functions, and pronunciation can be added to the cards.

\section{Research-Based Support for Word Cards}

\subsection{Previous Research}

In addition to the theoretical and indirect research-based support provided by the literature discussed above, there have been some empirical studies concerned specifically with the efficacy of word card study. Given the space constraints in this article, rather than describing the studies in detail, the main results of the papers are presented in Table 1.

\subsection{My Research on Word Cards}

In addition to the above research findings, the results of my own recent experiments have offered further support for word cards as a deliberate vocabulary study method.

In the first experiment, I aimed to determine the amount of short-term and long-term vocabulary learning that takes place from simply making words cards. This experiment was carried out as no research showing how much learning takes place from simply making word cards could be found. Nation and Webb (2011) state that "We know from experience that after making the cards, learners can recall from 30 to 70 percent of the meanings on the first run though the cards" (p. 42); however, experimental data backing up this claim have not been reported, as far as I am aware. Therefore, my experiment aimed to address this gap in the literature.

Table 1. Results of Studies on Word Cards

\begin{tabular}{ll}
\hline Findings & Researchers \\
\hline $\begin{array}{l}\text { Word card study results in significant } \\
\text { vocabulary knowledge gains }\end{array}$ & $\begin{array}{l}\text { Altiner (2011); Dodigovic (2013); Emrah and Omur } \\
(2010) ; \text { Komachali and Khodareza (2012); Kuo and }\end{array}$ \\
& $\begin{array}{l}\text { Ho (2012); Nakata (2008); Nikoopour and Kazemi } \\
(2014) ; \text { Waring (1997, 2004) }\end{array}$ \\
$\begin{array}{ll}\text { Word cards are a time-efficient method } \\
\text { of deliberate vocabulary study }\end{array}$ & $\begin{array}{l}\text { Komachali and Khodareza (2012); Kuo and Ho } \\
\text { (2012); Mondria and Mondria-de Vries (1994); } \\
\text { Nakata (2008); Waring (1997), }\end{array}$ \\
$\begin{array}{ll}\text { Word cards help students learn both } \\
\text { receptive and productive vocabulary }\end{array}$ & $\begin{array}{l}\text { Komachali and Khodareza (2012); Kuo and Ho } \\
\text { knowledge }\end{array}$ \\
$\begin{array}{ll}\text { Word card learning is superior to list } \\
\text { learning }\end{array}$ & $\begin{array}{l}\text { Kuo and Ho (2012); Mondria and Mondria-de Vries } \\
\text { (1994); Nakata (2008) }\end{array}$ \\
Learners show positive perceptions & Altiner (2011); Dodigovic (2013); Emrah and \\
toward word card use & Omur (2010); Kuo and Ho (2012); Nakata (2008); \\
& Nikoopour and Kazemi (2014) \\
\hline
\end{tabular}


The participants were first- and second-year students recruited from the two private universities in Tokyo. Three groups of learners were taken from three intact classes at one woman's university and one group from another private university. There were 72 participants (62 female and 10 male students) aged 18 to 21 years old. This was a convenience sample as the participants were chosen mainly due to ease of access. TOEIC (Test of English for International Communication) scores ranged from approximately 250 to 600, and all participants were enrolled in courses working towards improving their general English proficiency, but some wished to improve their scores on the TOEFL (Test of English as a Foreign Language), IELTS (International English Language Testing System), or TOEIC tests.

Based on the analysis of pretest, immediate posttest, and delayed posttest data from three word knowledge measures (passive recall, active recall, and written cloze), results suggest that the simple act of making word cards, without any deliberate study, produces statistically significant $(p<0.001)$ and pedagogically impressive learning outcomes. Immediately after making the cards, the mean gain score on the active recall knowledge measure was $60 \%$, that of the passive recall measure was $70 \%$, and the gain was $52 \%$ for the cloze measure. However, up to $50 \%$ of this new knowledge was lost by the delayed posttest stage. The results show that the process of making word cards results in considerable short-term memory gains and some long-term retention of target items. The results also indicate that the process of making word cards leads to better passive recall knowledge than active recall and knowledge of how to use the words in a given context. Overall, however, given that it took approximately 1 minute to make each card (15 minutes for 15 cards), and given the simple nature of the activity, these results seem quite impressive. However, significant forgetting also occurred during the 2-week period between the posttest and delayed posttest, proving that repeated study is needed after initially making the cards.

In another experiment, the learning outcomes attributable to (1) studying from premade word cards and (2) making and studying from word cards were examined. While we know that word cards are an effective deliberate study technique, I have been unable to find any carefully designed studies that compare the learning outcomes of studying from premade and self-made word cards. Therefore, it was unknown if it was better to (1) have students first make their own word cards before repeatedly studying from them or (2) spend the same total amount of time studying from premade word cards.

The participants were first- and second-year students recruited from the same two private universities mentioned above and taking similar classes. There were 85 participants aged 18 to 21 years old, whose TOEIC scores ranged from approximately 270 to 620 . The results of both the cross-sectional and longitudinal studies showed that both methods are effective for developing various types of word knowledge. Both word card methods produced significant short- and longterm vocabulary knowledge; however, in the short term, premade cards were superior in terms of all three types of vocabulary knowledge. These results suggest that in the short term, the extra number of repetitions afforded by the premade card method is more important than the extra involvement load induced by making word cards. However, in the long term, there was no significant difference between 
any of the measures of word knowledge. This showed that after 8 weeks of repeatedly studying the cards, the method of word card creation was not so important. Overall, the results provide further support for the use of word cards, whether they are self-made or premade, via a teacher's resource folder or a study app such as Quizlet. Furthermore, the results highlight the need for repeated study if learners are to transfer knowledge into long-term memory.

\section{Conclusion}

In summary, given the theoretical and empirical evidence provided by the current word card literature, and the results of the experiments briefly described above, there is ample evidence to support the use of word cards as a deliberate study method. Word cards offer a practical and portable method of deliberately studying vocabulary while being able to switch between active and passive recalls. In addition, students can implement expanded retrieval strategies by separating cards into packs based on how well they know the words and then reviewing more wellknown words less frequently than lesser known words. In addition, even a small amount of word card study can result in considerable short-term knowledge gains, and with repeated study this knowledge can be successfully transferred into longterm memory. Finally, it appears that studying from premade word cards may be just as effective, if not more so, as studying from self-made cards, meaning that many word card applications could be a suitable option for students who prefer this new platform.

\section{References}

Altiner, C. (2011). Integrating a computer-based flashcard program into academic vocabulary learning. Unpublished doctoral dissertation. Iowa State University. Retrieved from http://lib.dr.iastate.edu/cgi/viewcontent. cgi? article $=1122 \&$ context $=$ etd

Dodigovic, M. (2013). Vocabulary learning with electronic flashcards: Teacher design vs. student design. Voices in Asia Journal, 1, 15-33. Retrieved from www. viajournal.org/admin/file_upload_name/pp._15-33.pdf

Emrah, B., \& Omur, A. (2010). A comparison of undergraduate students' English vocabulary learning: Using mobile phones and flash cards. The Turkish Online Journal of Educational Technology, 9(3), 1-7. Retrieved from http://files. eric.ed.gov/fulltext/EJ898010.pdf

Folse, K. (2004). Vocabulary myths: Applying second language research to classroom teaching. Ann Arbor, MI: The University of Michigan Press.

Folse, K. (2011). Applying L2 lexical research findings in ESL teaching. TESOL Quarterly, 45(2), 362-369. doi: 10.5054/tq.2010.254529

Hulstijn, J. H. (2001). Intentional and incidental second-language vocabulary learning: A reappraisal of elaboration, rehearsal and automaticity. In P. Robinson (Ed.), Cognition and second language instruction (pp. 258-286). Cambridge University Press. 
Komachali, M. E., \& Khodareza, M. (2012). The effect of using vocabulary flash card on Iranian pre-university students' vocabulary knowledge. International Education Studies, 5(3), 134-147. doi: 10.5539/ies.v5n3p134

Kuo, Y., \& Ho, H. Y. (2012). Effects of word card strategy versus word list strategy on Taiwanese EFL junior high school students' vocabulary retention. Electronic Journal of Foreign Language Teaching, 9(1), 26-45. Retrieved from http://e-flt.nus.edu.sg/v9n12012/kuo.pdf

Laufer, B. (2003). Vocabulary acquisition in a second language: Do learners really acquire most vocabulary by reading? Some empirical evidence. Canadian Modern Language Review/LaRevue canadienne des langues vivantes, 59, 567587. doi: $10.3138 / \mathrm{cmlr}$.59.4.567

Mondria, J. A., \& Mondria-de Vries, S. (1994). Efficiently memorizing words with the help of word cards and "hand computer": Theory and applications. System, 22(1), 47-57. doi: 10.1016/0346-251x(94)90039-6

Nakata, T. (2008). English vocabulary learning with word lists, word cards and computers: Implications from cognitive psychology research for optimal spaced learning. ReCALL, 20(1), 3-20. doi: 10.1017/s09583440080002

Nation, I. S. P. (2013). Learning vocabulary in another language (2nd ed.). Cambridge University Press.

Nation, I. S. P., \& Webb, S. (2011). Researching and analyzing vocabulary. Boston, MA: Heinle Cengage.

Nikoopour, J., \& Kazemi, A. (2014). Vocabulary learning through digitized \& non-digitized flashcards delivery. Procedia-Social and Behavioral Sciences, 98, 1366-1373. doi: 10.1016/j.sbspro.2014.03.554

Schmitt, N. (2008). Review article: Instructed second language vocabulary learning. Language Teaching Research, 12, 329-363. doi: 10.1177/1362168808089921

Schmitt, N., \& Schmitt, D. (1995). Vocabulary notebooks: Theoretical underpinnings and practical suggestions. ELT Journal, 49(2), 133-143. doi: 10.1093/ elt $/ 49.2 .133$

Walters, J. D., \& Bozkurt, N. (2009). The effect of keeping vocabulary notebooks on vocabulary acquisition. Language Teaching Research, 13(4), 403-423. doi: $10.1177 / 1362168809341509$

Waring, R. (1997). A study of receptive and productive learning from word cards. Studies in Foreign Languages and Literature, 21, 94-114. Retrieved from http://www.robwaring.org/papers/various/wordcard.html

Waring, R. (2004) In defence of learning words in word pairs: But only when doing it the "right" way! Retrieved from http://wwwl.harenet.ne.jp/ waring/vocab/ principles/systematic_learning.htm 